\title{
De Badajoz a Málaga: Trayectoria del Portugués Estêvão de Brito como Maestro de Capilla
}

\section{From Badajoz to Málaga: Trajectory of the Portuguese Chapel Master Estêvão de Brito}

\author{
iD (9) Héctor Archilla Segade \\ Universidad de Extremadura, Badajoz, España \\ hectoras@unex.es
}

Resumen: Con objeto de aportar nuevas informaciones a las ya conocidas acerca de la estancia del maestro de capilla luso Estêvão de Brito en la Catedral de Málaga (1613 a 1641), se aborda el vaciado de las actas del cabildo de dicha catedral para poder reunir nuevas evidencias. La repentina marcha del músico portugués de su anterior destino, la catedral de Badajoz, conllevó una serie de situaciones que abordamos en este artículo, como fueron los intentos del Cabildo pacense por recuperarle, el proceso de oposición frente a otros maestros de capilla como Gabriel de Páez, Juan Gutiérrez de Padilla o Francisco Martínez de Ávalos, la gran influencia que continuó teniendo en la catedral pacense, al igual que la labor tanto artística como docente que llevó a cabo durante 28 años y su interés expreso por conservarla. Se presentan fuentes primarias inéditas y se referencian otras ya conocidas para su sencilla localización.

Palabras clave: Estêvão de Brito. Catedral. Málaga. Badajoz. Música Sacra. Siglo XVII.

\begin{abstract}
In order to provide new information to those already known about the stay of the Portuguese chapel master Estêvão de Brito in the Cathedral of Málaga (1613 to 1641), it has been made a review of this Cathedral cabildo's acts so as to collect new information. The sudden
\end{abstract}


departure of the Portuguese musician from his previous destination, Badajoz cathedral, entailed some situations addressed in this article such as the attempts of the Cabildo to make him back, the opposition process against other chapel masters such as Gabriel de Páez, Juan Gutiérrez de Padilla or Francisco Martínez de Ávalos, the great influence that he maintained on Badajoz cathedral, as well as the artistic and teaching work that he carried out for 28 years and his expressed interest in preserving it. Unpublished primary sources are presented and other sources already known are referenced for their easy location.

Keywords: Estêvão de Brito. Cathedral. Málaga. Badajoz. Sacred Music. XVIIth century.

Resumo: Com o propósito de oferecer nova informação à já conhecida sobre a estadia do mestre de capela português Estêvão de Brito na Sé de Málaga (1613 até 1641), procede-se ao esvaziamento das atas do capítulo da dita catedral para a recolha de novas evidências. A súbita saída do músico português do seu destino anterior, a Sé de Badajoz, conduziu a uma série de situações que serão abordadas neste artigo, como as tentativas do Capítulo pacense para o recuperar, o processo de oposição contra outros mestres de capela como Gabriel de Páez, Juan Gutiérrez de Padilla ou Francisco Martínez de Ávalos, a grande influência que continuou a ter na Sé de Badajoz, assim como o trabalho artístico e docente que foi desenvolvido por ele durante 28 anos e o seu interesse expresso em mantê-lo. Fontes primárias não publicadas são apresentadas e outras já conhecidas são referenciadas pela sua fácil localização.

Palavras-chave: Estêvão de Brito. Catedral. Málaga. Badajoz. Música Sacra. Século XVII.

Submetido em: 20 de agosto de 2020

Aceito em: 6 de fevereiro de 2021 
De Badajoz a Málaga: Trayectoria del Portugués Estêvão de Brito como Maestro de Capilla Héctor Archilla Segade

\section{Introducción ${ }^{1}$}

En nuestro interés por poner en valor y diseminar el trabajo realizado por el maestro de capilla portugués Estêvão de Brito (Serpa ca. 1577, Málaga 1641), queremos sacar a la luz informaciones que revelan la importante labor que realizó este músico formado en Évora (Portugal), siendo el responsable de la creación de una capilla estable de ministriles en la catedral de Badajoz y destacando su producción musical en Málaga.

En trabajos previos hemos abordado tanto su etapa como compositor en Badajoz como el estilo de su primer libro de motetes. Conscientes de la falta de información acerca de su estancia y labor musical durante casi treinta años en la ciudad de Málaga, y en vista de la existencia de dudosas afirmaciones publicadas sobre las circunstancias en las que dejó la catedral de Badajoz, surge la necesidad de producir este trabajo. Para su elaboración y mediante el vaciado de las actas capitulares de la catedral de Málaga, se ha llevado a cabo una búsqueda de nuevas evidencias que completen, corrijan y actualicen lo anteriormente divulgado.

La influencia de Brito fue crucial en la evolución de las capillas musicales de los citados templos y parte de su producción musical se conserva actualmente en Málaga, gracias a un interés personal del maestro, tal y como demuestra la carta autógrafa que presentamos en la última parte de este artículo.

Las actas capitulares de la catedral de Málaga, a diferencia de las de Badajoz, contienen pocos asientos de noticias relacionadas con la vida musical catedralicia. Aun así, tras su vaciado se ha encontrado información relevante con la que dar una visión completa sobre el transcurso del magisterio del maestro luso hasta su muerte.

\footnotetext{
1 Abreviaturas:

Archivo Catedral de Badajoz: E-BA

Archivo Catedral de Málaga: E-MA

Actas Capitulares: AC
}

Cabildo: Cab. 
De Badajoz a Málaga: Trayectoria del Portugués Estêvão de Brito como Maestro de Capilla Héctor Archilla Segade

Con todo ello, el presente trabajo pretende abordar y cerrar una parte de los vacíos que quedaban, al igual que abrir nuevas vías de investigación que podrían ser por un lado la discusión de la atribución de las obras de Brito, y por otro, la revisión de otras fuentes primarias como protocolos notariales de los archivos históricos provinciales de ambas ciudades que pudieran aportar nuevas informaciones acerca del músico. Estructuramos el artículo abordando en primer lugar la situación en la que queda la catedral de Badajoz ante la marcha de Brito, la oposición de Estêvão de Brito en la catedral de Málaga, el trabajo del músico en la nueva catedral y la conservación de su obra en el archivo de dicha catedral.

\section{"Y no gane del magisterio por hacerse partido sin embargo de licencia"}

Aunque temas como la ordenación sacerdotal, la oposición y toma de posesión del cargo como capellán, la perpetuación del salario de Estêvão de Brito, o su posterior marcha de Badajoz ya han sido abordados por investigaciones anteriores (ARCHILLA, 2013, 2018, 2019), queremos comenzar tratando este último tema en vista de nuevas noticias encontradas.

A pesar de haberse afirmado que esta repentina marcha a primeros de enero de 1613 no enturbió las relaciones del músico con la catedral pacense y que éstas continuaron siendo fluidas, no fue así en un primer momento. Para aclararlo, detallamos a continuación la marcha de Brito de la catedral de Badajoz a la de Málaga, que comienza el 9 de febrero con la solicitud de una licencia de dos meses para ausentarse ${ }^{2}$.

El maestro de capilla decide marchar sin esperar la respuesta correspondiente del Cabildo, y el 11 de enero éste determina dejar de pagarle el magisterio debido a su marcha sin permiso.

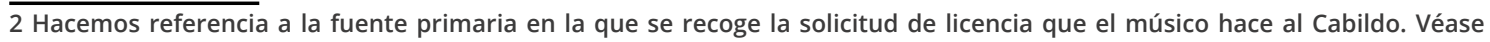
Archivo Catedral de Badajoz (E-BA), Actas Capitulares (AC) 1610-1616, fol. 148. 
De Badajoz a Málaga: Trayectoria del Portugués Estêvão de Brito como Maestro de Capilla Héctor Archilla Segade

Se encargará al músico Gil Fernández $z^{3}$ que asuma el cargo y se da por "vaca" la capellanía del coro que Brito ocupaba. Además, se hablará de la "descortesía y mal término" que el maestro de capilla había tenido".

Cinco días después se manifiesta en cabildo la mala actuación de Brito al salir de la ciudad para opositar a la plaza de maestro en la catedral de Málaga sin la correspondiente licencia, dejando sus obligaciones sin cubrir por otra persona tanto en el oficio de maestro de capilla como en el de capellán del coro, al igual que se confirma la falta de educación que tuvo ante el deán a quien habló con "palabras descompuestas" antes de marchar. La decisión de dejar vacante la capellanía del coro fue debida a que el Libro de Constituciones indicaba la imposibilidad de ausentarse tres días de la misma sin la correspondiente licencia del Cabildo. Esta decisión llevó consigo que se pusieran los correspondientes edictos para que pudiera cubrirse de nuevo 5 .

Kastner (1960, p. 65) comenta que mientras no se ocupaba la plaza en la catedral de Badajoz, el Cabildo pacense empleó en un primer momento a Manuel Rubio quien según él, "parece que hizo las veces del portugués", y después al capellán Sebastián Hernández. Además de estos dos, y según hace referencia Solís (1991, p. 89), también se ocupó del magisterio de la capilla Gil Fernández.

Como consideramos que estas afirmaciones no son del todo correctas y con el único objeto de aclarar la situación, se transcriben a continuación los asientos de estas actas:

3 El portugués Gil Fernández, oriundo de Olivenza, fue clérigo, presbítero y músico cantor contralto en la catedral de Badajoz. Es probable que hubiera recibido su formación musical en la Cátedra de Música que estableció en Olivenza el obispo de Ceuta, en 1539. Ingresa en la catedral de Badajoz como sochantre en 1570 integrándose como cantor contralto hasta 1613. A partir de este año ocupó durante unos meses el cargo de maestro de capilla que Brito dejó vacante. Para sustituir a Luis de Quiñoñes a su muerte en 1596 desempeñó el oficio de maestro de capilla interino. Aunque compuso obras musicales para la catedral de Badajoz, actualmente no se conserva ninguna.

4 Cabildo (Cab.) 11 de enero de 1613 E-BA, AC 1610-1616, fol. 148v.

5 Cab. 16 de enero de 1613 E-BA, AC 1610-1616, fol. 149. 
De Badajoz a Málaga: Trayectoria del Portugués Estêvão de Brito como Maestro de Capilla Héctor Archilla Segade

Viernes, 26 de abril de 1613: este día los dichos señores mandaron dar para ayuda a su camino a Manuel Rubio que pretende ser maestro de capilla cuatro ducados (o 44 reales) a cuenta de la fábrica 6 .

Viernes, 10 de mayo de 1613: (...) cometieron al Señor chantre con el Señor racionero Alonso Hormigo hagan sus mercedes inventario de los libros de la música y por cuenta y razón se le entreguen a Gil Fernández que de presente hace oficio de maestro7.

Último cabildo antes del día de San Juan. 21 de junio de 1613: maestro de capilla vacante . $^{2}$.

Miércoles 16 de octubre de 1613: Luego los dichos señores acordaron que Sebastián Hernández capellán enseñe a los mozos de coro de esta santa iglesia canto de órgano y canto llano cumpliendo en esto con la obligación de maestro en tanto que no le hay lo cual se satisfará.

Aportados estos datos, podríamos concluir que para cubrir las obligaciones que dejó del maestro luso, se puso al frente a Gil Fernández quien ocupó el cargo de maestro de capilla asumiendo también la responsabilidad de enseñar canto de órgano a los mozos de coro $^{10}$. En vista de que no era capaz de asumir correctamente esta obligación docente, se la encomendarán a Sebastián Hernández quien únicamente comenzó a enseñar canto de órgano y canto llano ${ }^{11}$. Por tanto, la única persona que desempeñó el cargo de maestro de capilla fue Gil Fernández al que también se le encargó valorar cuatro villancicos presentados por el músico Juan de la Rioja ${ }^{12}$.

El motivo más que probable de considerar erróneamente que, además de Gil Fernández, otras personas ocuparan el cargo de maestro de capilla sustituto, puede deberse a que, mientras

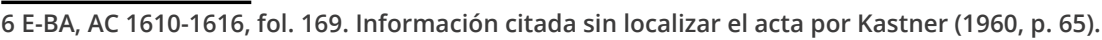
7 E-BA, AC 1610-1616, fol. 170v. 8 E-BA, AC 1610-1616, fol. 176v. 9 E-BA, AC 1610-1616, fol. 200. Citada sin localizar el acta y erróneamente datada por Kastner (1960, p. 65). 10 Cab. 26 de enero de 1613 E-BA, AC 1610-1616, fol. 151v. 11 Cab. 16 de octubre de 1613 E-BA, AC 1610-1616, fol. 200. 12 Cab. 22 de mayo de 1613 E-BA, AC 1610-1616, fol. 172.
} 
De Badajoz a Málaga: Trayectoria del Portugués Estêvão de Brito como Maestro de Capilla Héctor Archilla Segade

Gil Fernández asumió las labores de maestro de capilla, fueron varias las personas que de forma particular se interesan por ocupar el cargo. En un primer momento, Manuel Rubio, colegial en Évora, acude a Badajoz a mostrar su interés por el cargo y fue valorado por los músicos de la capilla ${ }^{13}$. Posteriormente presentó su candidatura el presbítero Domingo Martín ${ }^{14}$. Será finalmente la petición que llega el 4 de abril de 1614 de Marco Antonio Periáñez la que consideren válida ${ }^{15}$, quedando cubierta la plaza el 7 de abril de 1614 por dicho maestro de capilla, hasta su muerte el 7 de marzo de 1622.

Lunes 7 de abril de 1614: Este día entró el señor provisor en el cabildo con su acompañamiento acostumbrado y los dichos señores deán y cabildo, conformándose con la voluntad del dicho señor provisor, recibieron por maestro de capilla a Marco Antonio Periáñez con salario cada un año de ciento y treinta ducados y veinticuatro fanegas de trigo ${ }^{16}$.

Periáñez, del que se desconoce su procedencia anterior, había entrado a desempeñar el cargo de maestro de capilla en la catedral de Coria el 14 de junio de 1613. Desconocemos los motivos que le motivaron marchar a Badajoz, pero el hecho de los recortes a músicos con motivo de la maltrecha economía de la catedral de Coria, así como el haber estado preso, pudieron motivarle a salir de allí y probar suerte en la de Badajoz. (BARRIOS, 1999, pp. 67-93).

Aunque en un primer momento las relaciones de Brito con la catedral se enturbiaron, estas nunca llegaron a romperse. El Cabildo pacense tenía en muy alta estima la labor y gran aptitud del músico y podemos afirmar que el compositor mantuvo el contacto asesorando musicalmente a la catedral. Resulta un claro ejemplo cómo a la muerte de Periáñez, el Cabildo pedirá consejo al maestro luso sobre otros maestros de capilla idóneos para ocupar

13 Cab. 19 de abril de 1613 E-BA, AC 1610-1616, fol. 168v.

14 Cab. 19 de octubre de 1613 E-BA, AC 1610-1616, fol. 201.

15 E-BA, AC 1610-1616, fol. 225v.

16 E-BA, AC 1610-1616, fol. 226. 
De Badajoz a Málaga: Trayectoria del Portugués Estêvão de Brito como Maestro de Capilla Héctor Archilla Segade

su plaza. Aportamos algunos asientos de actas capitulares que nos muestran la recomendación que se hizo del maestro portugués Manuel Rodríguez Galván que fue el siguiente en ocupar el cargo de maestro de capilla:

\begin{abstract}
Viernes 3 de junio de 1622: Entró el señor provisor acompañado de cuatro señores capitulares más modernos y tratando del particular del maestro de capilla que ha venido, y de cómo el maestro Brito lo acredita por una carta, leer la dicha carta y habiendo discurrido en esta razón acordaron que haga actos y muestras de su habilidad el lunes que viene en el capítulo con los músicos ${ }^{17}$.

Jueves 9 de junio de 1622: Este día habiendo hecho actos Manuel Rodríguez Galván que pretende ser maestro de capilla en esta santa iglesia y dado muestras de su habilidad y suficiencia e informado cerca de ella las personas diputadas considerando ser el que conviene conforme lo aseguró el maestro Brito cometieron a los señores Licenciado Alonso Pérez y Don García de Alvarado canónicos traten sus mercedes de concierto el cual sea el más moderado que se pueda, y este nombramiento se entienda por el año que viene, y que se le notifiquen sus obligaciones habiéndose tomado asiento ${ }^{18}$.
\end{abstract}

Manuel Rodríguez Galván, desempeñó el magisterio en la capilla musical de la catedral pacense desde el 10 de junio de 1622 hasta septiembre del año siguiente con un salario de 18620 maravedíes y dos cahices de trigo. Fue el primero de una lista de tres maestros lusos consecutivos que le sucederían: Juan Díaz, Francisco Pinto Piñero y Alonso Vaz de Acosta, lo que pone de manifiesto una predilección en Badajoz mostrada por los maestros portugueses. Esta inclinación no fue simple coincidencia, sino que estuvo motivada por el asesoramiento de Brito y que terminó después de su muerte, ya que no se volvió a contratar maestro de capilla luso. 
De Badajoz a Málaga: Trayectoria del Portugués Estêvão de Brito como Maestro de Capilla Héctor Archilla Segade

Aunque muchas pudieron ser las causas que llevaron a Estêvão de Brito a abandonar la catedral de Badajoz para opositar a una plaza en la de Málaga, nos decantamos por la económica, en vista de diversas noticias que aparecen en actas capitulares como la del viernes 19 de abril de 1613, donde se confirma "la petición de Esteban de Brito maestro de capilla que fue de esta santa iglesia, en razón de su salario"19, tratando más adelante de ofrecer al músico su vuelta a Badajoz ${ }^{20}$.

A pesar de estos intentos por recuperarle, el 22 de enero de 1614, una vez leída la esperada respuesta de Brito, se decide poner edictos para proveer la capellanía del coro que estaba vacante ${ }^{21} y$ que cubrirá el sacristán Juan de Borba, en vista de la decisión del maestro de capilla por quedarse en Málaga ocupando la plaza que acababa de ganar, tal y como indican las actas de la catedral de Málaga:

Se trataba de la plaza que había dejado vacante al morir Francisco Vázquez a mediados del año 1612. Conocedores de la vacante algunos maestros de capilla, entre los que muy probablemente se encontraba Brito, para mostrar su trabajo habían enviado a Málaga sus Chanzonetas que fueron aprovechadas en las fiestas de Pascua de los Reyes de la catedral ${ }^{22}$.

Habiendo abordado la marcha de Brito de Badajoz, y aclarado algunos de los errores que sobre este particular existían, trataremos a continuación la llegada del músico a su nuevo destino. Asimismo, se presentan algunas novedades que nos muestran los libros de Actas de Cabildo sobre el trabajo que allí desarrolló durante los veintiocho años posteriores hasta su muerte.

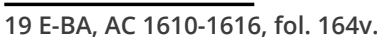

20 Cab. 25 de septiembre de 1613 E-BA, AC 1610-1616, fol. 196v.

21 Sobre la provisión de la capellanía que dejó vacante el maestro Brito, véase: E-BA, AC 1610-1616, fols. 150v, 151, $151 \mathrm{v}, 156 \mathrm{v}, 214$. 22 Cab. 29 de diciembre de 1612. E-MA, AC 1609-1615, fol. 224. 


\section{"Y votado por él salió nombrado Esteban Brito nemine discrepante"}

Sobre el inicio de la oposición en Málaga, vemos que todo comienza a finales de 1612 con la recepción de obras musicales de los aspirantes al puesto, tal y como se indica en la siguiente acta capitular del 29 de diciembre de 1612:

En la ciudad de Málaga en veintinueve de diciembre de seis y doce años se juntaron a Cabildo (...) y allí juntos acordaron lo siguiente: (...) El Señor. Presidente propuso como algunos Maestros de Capilla habían enviado Chanzonetas y que sería justo que se cantasen en Pascua de los Reyes y el Cabildo cometió al Sr. Arcediano de Ronda que haga que los cantores acudan a probarlas y las canten la dicha pascua y que las pueda poner conforme le pareciere no acudiendo a sus obligaciones ${ }^{23}$.

Otros asientos de las actas capitulares que aportamos a continuación van detallando este proceso de oposición que se desarrolló bajo la supervisión del organista Juan de Cisneros ${ }^{24}$ :

\footnotetext{
En veintitrés de enero de seiscientos y trece años se opuso a la ración de maestro de capilla Estevan de Brito maestro de capilla de Badajoz.

En veinticuatro de enero de seiscientos y trece el Racionero Francisco de Noguerol se opuso a la ración de Maestro de capilla en nombre de Francisco Martínez de Ábalos y con su poder maestro de capilla de Úbeda.

El dicho en el dicho día se opuso con poder de Fulgencio Méndez Avendaño maestro vecino de Murcia.

Este dicho día Pedro Marañón vecino de esta ciudad se opuso a la dicha ración por Gabriel Páez vecino de Palencia.
}

\footnotetext{
23 Archivo Catedral de Málaga (E-MA), AC 1609-1615, fol. 224.
} 24 Cab. 23 de enero de 1613. E-MA, AC 1609-1615, fol. 228v. 
De Badajoz a Málaga: Trayectoria del Portugués Estêvão de Brito como Maestro de Capilla Héctor Archilla Segade

Los edictos quedaron abiertos hasta un día más tarde, una vez que acabaron las pruebas de oposición:

En la ciudad de Málaga en nueve de febrero de seiscientos y trece años se juntaron a Cabildo (...) y así juntos acordaron lo siguiente. (...) Habiendo el Señor Presidente propuesto costar [que] hoy se cumplan los edictos de la Ración de Maestro de capilla acordó el Cabildo que los dichos edictos se queden abiertos por el tiempo que durasen los ejercicios y un día más y que los señores Don García Hernández y Don Juan Çapata vayan al Sr. Obispo y le den cuenta de lo dicho y que este Cabildo nombra al Racionero Cisneros por examinador y fueran los señores comisarios que escoja el señor obispo ${ }^{25}$.

Cinco fueron los músicos que se opusieron: Esteban de Brito, maestro de capilla en la catedral de Badajoz; Juan Gutiérrez de Padilla, maestro de capilla en la Iglesia Colegial de Jerez de la Frontera (Cádiz); Francisco de Ávila y Páez, maestro en el Convento de las Descalzas de Madrid; Francisco Martínez de Ávalos, maestro de capilla en la Sacra Capilla del Salvador de Úbeda; y Fulgencio Méndez Avendaño, maestro de capilla de Murcia.

Terminadas las pruebas, cerrados los edictos y votado a los candidatos por parte del Cabildo, el resultado fue tan claro como unánime saliendo "nombrado en él Esteban Brito maestro de capilla de Badajoz con diez y siete votos que fue todo el Cabildo nemine discrepante quedando en segundo lugar Juan Gutiérrez"26.

A partir de este momento Brito comenzó a trabajar, mientras se hacían las comprobaciones de limpieza de sangre pertinentes, siendo tenido en cuenta y consultado para todos los temas referentes a la música en la nueva catedral:

25 Cab. 9 de febrero. E-MA, AC 1609-1615, fol. 232.

26 Cab. 16 de febrero de 1613. E-MA, AC 1609-1615, fols. 233, 234. 
De Badajoz a Málaga: Trayectoria del Portugués Estêvão de Brito como Maestro de Capilla Héctor Archilla Segade

Propuso el señor Arcediano que el racionero [ilegible] ha hecho relación que en la iglesia de en el reino de Portugal hay un cantor tiple de veintidós años que y haciéndole alguna comodidad para poder sustentarse vendría a esta iglesia la cual padece la necesidad que es notoria que vea el cabildo qué convendrá hacer para que [ilegible]. Acordose que el señor doctor García escriba al racionero Brito que trate con el dicho cantor la disposición que tiene para venir y que traiga muy tanteado este negocio para que habiendo oído el cabildo al dicho racionero Brito se tome resolución ${ }^{27}$.

Una vez hechas las comprobaciones de limpieza de sangre "el Cabildo nombró al señor Arcediano de Vélez y al señor Don Juan Çapata para que la lean y la vean con el Señor Obispo"28. El 2 de mayo de 1613 se aprobó la información del racionero Brito nemine discrepante ${ }^{29}$ que, según Querol (1972) tomó posesión de su cargo el 8 de mayo de dicho año hasta su muerte hacia el 2 de enero de 1641.

\begin{abstract}
En la ciudad de Málaga a ocho de mayo del dicho año los dichos señores, Deán y Cabildo se juntaron. (...) Entró Esteban Brito [ilegible] en la ración del maestro de capilla y presentó los testigos de la información [ilegible] de su magestad [sic] colación y canónica institución de su señoría el señor Obispo de esta ciudad y pidió al cabildo le den la posesión de la dicha ración y habiéndolo visto y leído los dichos [ilegible] y que sus probanzas estaban [ilegible] mandaron que se le dé la participación de la dicha ración que cometieron el darla a los señores Doctor [ilegible] y Licenciado Don Juan Çapata los cuales se la dieron quieta y pacíficamente ${ }^{30}$.
\end{abstract}

Una vez que el maestro luso consigue su ración de maestro de capilla y es oficialmente contratado, trabajará únicamente en

27 Cab. 13 de noviembre de 1613. E-MA, AC 1609-1615, fol. 242v.

28 Cab. 13 de abril de 1613. E-MA, AC 1609-1615, fol. 244.

29 E-MA, AC 1609-1613, fol. 247v.

30 E-MA, AC 1609-1615, fol. 248v. 
De Badajoz a Málaga: Trayectoria del Portugués Estêvão de Brito como Maestro de Capilla Héctor Archilla Segade

Málaga, aunque su ambición le lleva a opositar a una plaza en la corte real que desafortunadamente no consigue. Las noticias que atesoran las actas de la catedral malagueña nos muestran cómo las decisiones musicales se dejaron siempre en manos del maestro portugués, quien tuvo que tomar decisiones acerca de cómo debían de repararse los libros de canto de órgano ${ }^{31}$, hacer la tabla de los oficios de la semana ${ }^{32}$ o recomendar la contratación de cantores para su capilla musical ${ }^{33}$.

Como detalla Archilla (2016, p. 236), dentro de la catedral, Brito vivió entre otras, la provisión de la ración de órgano que estaba sin ocupar en aquel momento, aunque el diácono malagueño Ginés Barçer era la persona encargada de tocarlo ${ }^{34}$. La plaza la ocupó Luis Páez Maluenda, de quien encontramos noticias como racionero organista en $1615^{35}, 1618^{36}$ y $1633^{37}$.

Tenemos constancia del salario de Brito en abril de 1613, cuando se indica al mayordomo que entregara "doce ducados cada mes al maestro de capilla para su sustento" ${ }^{\prime 38}$. Este sueldo suponía un total de 54000 maravedíes al año, lo que eran 8000 maravedíes más que en la catedral de Badajoz sólo por su trabajo como maestro de capilla.

\section{"Y que respeten al maestro y lo obedezcan en materia de su oficio"}

Como exponen autores como Torrente (2016), las obligaciones de los miembros de las capillas musicales en las catedrales españolas no variaban demasiado ya que las Constituciones eran

\footnotetext{
31 Cabs. 5 y 11 de diciembre de 1614. E-MA, AC 1609-1615, fols. 319v, 324.

32 Cab. 12 de abril de 1615. E-MA, AC 1609-1615, fol. 364v.

33 Destacamos la recomendación de un cantor tiple portugués que puede verse en Cab. 11 de abril de 1613. E-MA, AC 16091615 , fol. 242v.

34 Ver Cab. 3 de marzo de 1614. E-MA, AC 1609-1615, fols. 282v, 283; Cab. 5 de marzo de 1614. E-MA, AC 1609-1615, fol. 284; Cab. 12 de julio de 1614. E-MA, AC 1609-1615, fol. 289; Cab. 5 de septiembre de 1614. E-MA, AC 1609-1615, fol. 309v; Cab. 5 de diciembre de 1614. E-MA, AC 1609-1615, fol. 319v, 320;

35 Cab. 5 de marzo de 1615. E-MA, AC 1609-1615, fols. 319v, 350.

36 Cabs. 16 de mayo de 1618 y 6 de julio de 1618. E-MA, AC 1615-1620, fols. 339, 348v.

37 Cab. 6 de junio de 1633. E-MA, AC 1633-1639, fol. 32.

38 E-MA, AC 1609-1615, fol. 250v.
} 
De Badajoz a Málaga: Trayectoria del Portugués Estêvão de Brito como Maestro de Capilla Héctor Archilla Segade

muy similares entre ellas. Corroboramos que este hecho también se da en Málaga, una vez vistos los distintos asientos que sobre la vida musical de esta catedral aparecen en sus actas capitulares. Además, todos ellos nos muestran un devenir muy similar al de la catedral pacense a pesar de que el número de noticias registradas en Málaga es mucho menor. En ellas podemos ver a un maestro de capilla asumiendo, entre otras cosas, las labores didácticomusicales impartiendo "dos lecciones de canto de órgano" diarias 39 .

Dar clases y asistir a las horas eran obligaciones que el maestro no debía descuidar y a Brito se le descontarán por primera vez en 1614, dos ducados por faltar un día tanto a las horas como a dar su lección ${ }^{40}$. Lo más probable es que la causa de no cumplir con esta obligación fuera la de acudir junto con sus cantores a amenizar alguna fiesta fuera de la iglesia, ya que el mismo asiento hace referencia a una prohibición a acudir los cantores a fiestas externas "por las faltas que hacen".

Tocar en otros lugares era una práctica habitual en los músicos de la época y aunque volvemos a encontrar el 20 de julio de 1615 otra negativa para que los ministriles salieran "a tañer a otras partes" por la misma causa de faltar a sus obligaciones ${ }^{41}$, el Cabildo permitió a estos músicos en otras muchas ocasiones, ir a tocar a fiestas de localidades cercanas a Málaga como la villa de Cártama ${ }^{42}$, Coín ${ }^{43}$ o Venamocarra ${ }^{44}$.

El trabajo del maestro de capilla con sus músicos no tuvo que ser fácil. En las actas capitulares encontramos que los problemas con los miembros de la capilla, debidos a su mal comportamiento, fueron frecuentes. Son muchos los cabildos en los que se les recuerda "acerca de la obligación que todos tienen del servicio del choro" 45 y varias las ocasiones en las que se impone una

\footnotetext{
39 E-MA, AC 1609-1615, fol. 250v.

40 Cab. 8 de enero de 1614. E-MA, AC 1609-1615, fol. 275v. 41 E-MA, AC 1615-1620, fol. 25v.

42 Cab. 5 de mayo de 1617. E-MA, AC 1615-1620, fol. 188. 43 Cab. 31 de enero de 1618. E-MA, AC 1615-1620, fol. 297. 44 Cab. 24 de abril de 1618. E-MA, AC 1615-1620, fol. 334. 45 Cab. 5 de junio de 1615. E-MA, AC 1615-1620, fol. 23.
} 
De Badajoz a Málaga: Trayectoria del Portugués Estêvão de Brito como Maestro de Capilla Héctor Archilla Segade

sanción económica a causa de la indisciplina de estos cantores y ministriles ${ }^{46}$.

Nos llama la atención el caso particular del salmo Miserere que debían interpretar en la capilla del santo "los viernes de cuaresma acabadas las completas en el coro" junto con "un motete de la pasión" y la lectura del versículo acostumbrado. No solo no cumplieron con su obligación, sino que además formaron un "ruido y alboroto nunca visto". Ante esta situación, el Cabildo tuvo que contratar a músicos 'extravagantes' ajenos a la capilla para que se cubrieran las obligaciones que los integrantes de la capilla musical no hacían ${ }^{47}$, volviendo a tener que contratar músicos 'forasteros' para cantar las chançonetas", "ayudar a los oficios divinos"49, a los "maitines de la pascua" $50 \mathrm{O}$ "al facistol"51.

De manera reiterada, el Cabildo pedía que se recordara a cantores y ministriles las obligaciones que no cumplían y que eran entre otras: cantar el Miserere los viernes de la cuaresma ${ }^{52}$, "guardar el oficio diurno por el discurso de todo el año"53, probar las chançonetas y motetes ${ }^{54}$, comportarse correctamente durante los ensayos ${ }^{55}$, estudiar y ensayar lo que pidiera el maestro de capilla además de obedecerle y respetarle.

Sobre esto último, incluimos dos asientos en los que Brito muestra su descontento con los integrantes de la capilla por no ponerse a sus órdenes, así como por no estudiar lo suficiente:

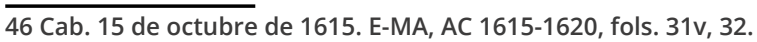
47 Cab. 3 de marzo de 1618. E-MA, AC 1615-1620, fols. 308-309. 48 Cab. 17 de enero de 1618. E-MA, AC 1615-1620, fol. 294v. 49 Cab. 7 de julio de 1617. E-MA, AC 1615-1620, fol. 216v. 50 Cab. 16 de enero de 1619. E-MA, AC 1615-1620, fol. 382v. 51 Cab. 2 de agosto de 1619. E-MA, AC 1615-1620, fol. 409. 52 Cab. 8 de marzo de 1618. E-MA, AC 1615-1620, fol. 310. 53 Cab. 21 de marzo de 1618. E-MA, AC 1615-1620, fols. 317v, 318.

$54 \mathrm{El}$ maestro de capilla se queja en varias ocasiones de que los músicos no acuden a probar las chançonetas que componía. Ver Cab. 13 de noviembre de 1614. E-MA, AC 1609-1615, fol. 315v; Cab. 11 de marzo de 1619. E-MA, AC 1615-1620, fol. 389v; 55 Cab. 11 de diciembre de 1614. E-MA, AC 1609-1615, fol. 322. 
De Badajoz a Málaga: Trayectoria del Portugués Estêvão de Brito como Maestro de Capilla Héctor Archilla Segade

20 de abril de 1616: Nombró el Cabildo a los señores Don Diego de Vargas y Don Diego Enríquez para que hablen a los músicos cerca de lo que el maestro de capilla representó en este Cabildo de que estudien y que respeten al maestro y lo obedezcan en materia de su oficio y que hablen a su señoría acerca de que haya seises ${ }^{56}$.

Lunes, 18 de mayo de 1620: El racionero Brito entró en este cabildo a hacer relación que los ministriles no cantaban ni tañían ni hacían ejercicios y advirtió de otras cosas tocantes a la música y suplico al cabildo pusiese remedio en esto y se salió. El cabildo habiendo tratado sobre el caso acordó que el señor Don Diego Enríquez hable sobre que haya remedio en que los músicos y ministriles hagan ejercicio de música al maestro de capilla ${ }^{57}$.

Esta constante indisciplina por parte de ministriles y cantores podemos explicarla, por un lado, porque Brito no mostraba la autoridad suficiente, y por otro, porque las consecuencias no eran demasiado graves. Todo ello sumado a que el Cabildo solucionaba muchas de las situaciones buscando otras personas que cubrieran de manera temporal las faltas de los músicos y a que las multas impuestas terminaban por rebajarlas o condonadas ${ }^{58}$.

\section{"Y salió por abas negras nemine discrepante que no se le diesen las horas"}

Durante su magisterio, Brito gozó de los permisos que solicitó a condición de no fallar "a sus obligaciones del coro"59. Los más recurridos fueron los solicitados tanto para componer como para probar las chançonetas ${ }^{60}$ : una de las obligaciones en la que Brito

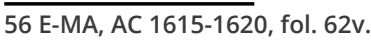

57 E-MA, AC 1615-1620, fol. 459.

58 Acerca de las multas que se quitaron a otros músicos como el cantor tiple Joan Muñoz o el organista Luis Páez, pueden verse los Cabs. 2 y 15 de octubre de 1615. E-MA, AC 1615-1620, fols. 29, 31v, 32. Sobre músicos que se negaron a cantar y contrapuntear el día de Pascua, ver Cab. 5 de abril de 1619. E-MA, AC 1615-1620, fol. 392v.

59 Cab. 12 de diciembre de 1616. E-MA, AC 1615-1620, fol. 143.

60 Sobre la solicitud de permisos para componer las chançonetas del Corpus, ver Cabs. 6 de mayo de 1616 y 26 de abril de 1617. E-MA, AC 1615-1620, fols. 67v y 185. 
De Badajoz a Málaga: Trayectoria del Portugués Estêvão de Brito como Maestro de Capilla Héctor Archilla Segade

tenía que invertir más tiempo tanto para Navidad como en el Corpus. Esta dedicación le impedía atender a todas sus obligaciones diarias.

Acostumbrado a que en la catedral de Badajoz se le liberaba de dichos deberes mientras las componía, el 13 de octubre de 1613 solicitó "que por el tiempo que se le tuviere ocupado en componer chançonetas mande el Cabildo que le den las horas". Este permiso le fue concedido durante el tiempo en el que "estuviese ocupado en el dicho ministerio"61 que solían ser unos veinte días ${ }^{62}$, hasta que en 1616 se toma la decisión de no liberarle de horas para este menester en vista de que los maestros anteriores no habían tenido este privilegio.

Miércoles, 9 de noviembre de 1616: Propuso el Señor Deán que el Maestro de capilla había entrado en el Cabildo pasado y pedido en él se le dicen las horas todo el tiempo que se ocupase en hacer las chanzonetas para la Pascua de navidad que viese el Cabildo si se le habían de dar y habiendo tratado y platicado sobre ello acordó que se vote por abas [sic] blancas y negras si se le darán luego las horas o si se las dará hasta que se vean actas capitulares por donde consta que se le piden dar las horas a los maestros de capilla para este ministerio de componer las chanzonetas significando la aba [sic] blanca que se le den las horas luego y la negra que no se le den hasta que se vean las actas capitulares que sobre esto hubiere habido y en esta conformidad se dieron abas [sic] blancas y negras a todos los dichos señores capitulares y salió por abas [sic] negras nemine discrepante que no se le diesen las horas hasta que no se viesen los autos capitulares y la orden que se ha venido con los dichos maestros de capilla sobre esta pretensión. Luego cometió el Cabildo al Señor Arcediano de Vélez, vea y busque las dichas actas capitulares y haga relación de ellos el Cabildo ${ }^{63}$.

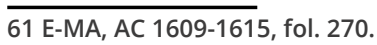

62 Cab. 20 de abril de 1616. E-MA, AC 1615-1620, fol. 62. 63 E-MA, AC 1615-1620, fol. 131. 
De Badajoz a Málaga: Trayectoria del Portugués Estêvão de Brito como Maestro de Capilla Héctor Archilla Segade

Jueves 10 de noviembre de 1616: El Señor Arcediano de Vélez comisario para buscar los autos capitulares antigos [sic] donde el Cabildo hubiese dado las horas al maestro de capilla el tiempo que se ocupase en componer las chanzonetas de la pascua de navidad y fiesta del Corpus. Hizo relación en este Cabildo de que había buscado en un libro antiguo las dichas actas capitulares y que no halló ninguno donde al maestro de capilla se le hubiesen dado horas para componer chanzonetas, que sólo había hallado algunos donde el cabildo se las había dado a él y a los cantores para probarlas algunas de las actas de las dichas fiestas en que se había de cantar. Y consta relación el cabildo volvió a votar se le darían las horas al dicho maestro de capilla como las había pedido y se ha determinado nemine discrepante que no se le den pues a sus antecesores no se le han dado ${ }^{64}$.

\section{"Y hubo presentes y ausentes: el maestro de capilla Brito en patitur"}

Brito ocupó la plaza de maestro en la catedral de Málaga hasta su muerte en 1641. Aunque no hemos encontrado dato alguno sobre la fecha exacta de su fallecimiento ni alusión a ello, se desgrana a continuación lo que sabemos acerca de su enfermedad y últimos días de su magisterio.

Próximo a la marcha de Brito de la catedral de Badajoz, el maestro se ausentó en algunas ocasiones por estar enfermo. Encontramos también en Málaga muestras de la enfermedad de Brito al no poder encargarse de componer ni probar las chançonetas de la Pascua de Navidad en 1617. Ambas tareas le son encargadas al Racionero Garzón a quien se le dan las horas para ocuparse de ello65.

El 3 de octubre de 1640 tenemos la noticia que nos informa sobre la enfermedad de Brito, al indicarse su ausencia en el cabildo:

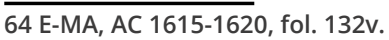

65 Cabs. 31 de octubre y 8 de noviembre de 1617. E-MA, AC 1615-1620, fols. 272, 272v, 274. 
De Badajoz a Málaga: Trayectoria del Portugués Estêvão de Brito como Maestro de Capilla Héctor Archilla Segade

"maestro de capilla Brito en patitur"66. Además, el 12 de noviembre de dicho año vemos que no puede encargarse de componer las chanzonetas de Pascua por seguir enfermo. Como anteriormente ya habíamos referido a alguna 'baja' por enfermedad del maestro de capilla, nada hace esperar que esta baja pudiera desencadenar con la muerte del mismo un año después. Las citadas chanzonetas fueron encargadas a Mateo Serrano:

Málaga, doce de noviembre de 1640: Entró el maestro de capilla y dijo que bien sabía este Cabildo cómo había venido a esta santa iglesia un cantor thenor y es sochantre de Monte Santo y otro contralto y que ambos eran voces muy buenas y en quien este cabildo podía hacer cualquier gracia y (...) salario y que así mismo para que Matheo Serrano haga las chanzonetas para esta Pascua respecto de estar el otro maestro enfermo y con esto se fue ${ }^{67}$.

Entendemos que aún con Brito enfermo la vida musical de la capilla continuó, asumiendo un maestro sustituto de manera intermitente las obligaciones del cargo. Desconocemos el nombre de este maestro sustituto, ni si lo hubo, y qué tiempo sustituyó a Brito ya que en la mayor parte de las noticias obtenidas de los asientos de las actas capitulares se hace referencia al maestro de capilla sin indicar nombre alguno.

Es por ello que el 15 de noviembre, no tenemos seguridad de que fuera Brito o su sustituto quien contrató a nuevos cantores (tenor y contralto) para la catedral:

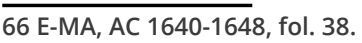
67 E-MA, AC 1640-1648, fols. 44v-45. 
De Badajoz a Málaga: Trayectoria del Portugués Estêvão de Brito como Maestro de Capilla Héctor Archilla Segade

Málaga, quince de noviembre de 1640: Entró demandado a este cabildo el maestro de capilla que hizo relación del examen que ayer hizo el sochantre del monte santo de Granada y el de esta santa iglesia opuesto al thenor y que le pareció es muy buena voz el de Granada y muy apropiado y considerado lo uno y lo otro y habiéndose oído el dicho maestro de capilla, votando sobre si se habría de proceder a la cesión de la otra ración o se había de dar relación, el cabildo por mayor parte, acordose le dé salario al otro sochantre del monte santo68.

Las últimas noticias que tenemos del músico portugués son la que nos deja por un lado el cabildo de 20 de noviembre de 1640, en el que Brito aporta al igual que otros compañeros suyos un donativo de "cien francos de plata" a favor de su Majestad69; y por otra parte la reseña de que en vista de que "Ios músicos, cantores y ministriles" no cumplían con su trabajo a pesar de las sanciones que les imponía el maestro Brito, fueron llamados a cabildo para reprenderles por ello y pedirles que lo hicieran ${ }^{70}$. Asimismo, en este cabildo de 14 de diciembre de 1640, se pide a Brito que cumpla con su obligación de "enseñar canto de órgano" nombrando él mismo a una persona que lo hiciera en su lugar"71.

Probablemente, su delicado estado de salud le impedía estar tan implicado con el buen funcionamiento de la capilla y el 25 de marzo de 1641 se acuerda que "el oficio de maestro de capilla lo haga el Racionero Francisco de Mangas"72, quien formaba parte de la misma desde que obtuviera, el 23 de octubre de 1634 nemine discrepante, la ración de contrabajo ${ }^{73}$.

El folio 81 correspondiente al Libro de Actas Capitulares de 1640 a 1648 hace referencia al cabildo que tuvo lugar el 20 de julio de 1641. Sin embargo, la siguiente página, sin numerar, se encuentra vacía con una anotación situada en el centro de la hoja

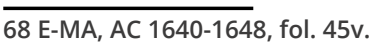
69 E-MA, AC 1640-1648, fol. 47. 70 E-MA, AC 1640-1648, fol. 51v. 71 E-MA, AC 1640-1648, fol. 52. 72 E-MA, AC 1640-1648, fol. 67. 73 E-MA, AC 1633-1639, fols. 161v, 162. 
De Badajoz a Málaga: Trayectoria del Portugués Estêvão de Brito como Maestro de Capilla Héctor Archilla Segade

en la que se lee "blanca". Aunque el siguiente folio sí está numerado como 82 recoge la información referente al cabildo reunido el 2 de diciembre de ese mismo año, donde se determina la puesta de edictos para cubrir la ración de maestro de capilla de la siguiente manera:

Málaga, en dos días del mes de diciembre de 1641: Tratáronse sobre si se ha de poner edictos de la ración entera de Maestro de Capilla no embargante que haya venido el racionero Roldán a esta ciudad con intento de oponerse. Y conferido sobre ello largamente, hubo ocho votos en que si fuese el dicho racionero Roldán, y si no se fuese, no se pusiesen edictos a la ración en que entra la parte del Señor Obispo. Y otros ocho votos en que votaron en que se pusiesen los edictos. Y visto esto se acordó se acuda al Señor Obispo para que vea lo que hay que hacer ${ }^{74}$.

Hay, pues, un lapso de tiempo comprendido entre julio y diciembre, no recogido en las actas capitulares, que nos indica que el fallecimiento del maestro Brito sucedió durante estos meses e imposibilitando datar esta fecha a la espera de algún otro documento que lo atestigüe.

Brito fallece a la edad de 66 años, dedicados en su mayor parte a la labor musical habiendo abarcado labores interpretativas, compositivas y docentes. En la catedral de Málaga le sucederá en 1642 el racionero citado anteriormente, Juan Pérez Roldán.

\section{"Y se punten en pergamino para que así duren, y el servicio del choro no padezca"}

Miguel Querol Gavaldá no sólo identificó la obra de Brito que se encontraba desordenada en la catedral malagueña, sino que también inventarió todos los manuscritos que contenían la música de Brito. Algunos de estos manuscritos datan de comienzos del siglo XVII, momento en el que Brito trabajó en Málaga, mientras

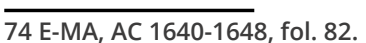


De Badajoz a Málaga: Trayectoria del Portugués Estêvão de Brito como Maestro de Capilla Héctor Archilla Segade

que otros son del siglo XVIII. En toda esta producción musical, conservada en Málaga, no se encuentra villancico alguno de todos los que el maestro compuso. Tampoco se guarda un libro de Missas recogido en un inventario de 1859. Sabemos también que la biblioteca del Rey João IV albergó obras del músico que actualmente, debido al terremoto y posterior incendio de Lisboa, no se conservan. (ARCHILLA, 2016, p. 21).

Podríamos asegurar que la totalidad de la producción musical que de Brito se conserva actualmente en la península se encuentra afortunadamente en buen estado en el archivo de la catedral de Málaga donde puede consultarse. El inventario de Querol ha sido posteriormente ampliado por Antonio Martín Moreno dando lugar a un catálogo completo del archivo de música ${ }^{75}$.

En Badajoz tampoco se atesoran partituras del maestro. Sin duda fue un período complicado en el que los robos ocurridos a lo largo de más de tres siglos durante las guerras con Portugal y sobre todo en la guerra de la Independencia en el XIX, hicieron que desaparecieran una gran parte de las obras que en él estuvieron, así como "Ios papeles manuscritos de los siglos XVI y XVII en su totalidad", afirma Solís (1993, p. 15). En este sentido, la situación en Málaga es muy similar ya que apenas se conservan obras musicales pertenecientes a estos siglos, llamando la atención que haya tanta música del portugués.

Las causas podrían ser varias. Por un lado, Rees (2019, p. 50) relaciona la elevada cantidad de obras conservadas del maestro con el prestigio que su música tenía en la ciudad, pero además de esta posibilidad, mostraremos como casusa posible el expreso deseo de Brito por conservar la música que apuntamos a continuación.

El manuscrito II corresponde al Liber Primus Motectorum, compuesto por 26 composiciones a 4, 5, 6 y 8 voces. El Ms. IV, se trata de Officium defunctorum, conformado por nueve piezas, siendo dos de ellas de Cristóbal de Morales (catalogado como P.11). Psalmis Hymnique per Natum, un conjunto de 36 obras con salmos, himnos, fabordones, de 1635 se encuentra en el Ms. VII (numerado

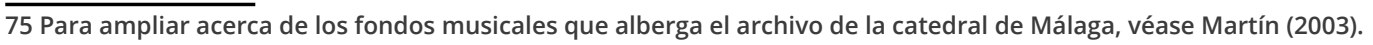


De Badajoz a Málaga: Trayectoria del Portugués Estêvão de Brito como Maestro de Capilla Héctor Archilla Segade

como P.2 en el catálogo del archivo). Las quince composiciones del manuscrito VIII, a 4, 5 y 6 voces, conforman el Motectorum altera colectio, conteniendo el Ms. IX un total de 30 obras de varios autores (Cristóbal de Morales, Francisco Vázquez y Juan Navarro), entre las que hay himnos y lamentaciones (numerado en el catálogo como P.8). Por último, 21 himnos y salmos conforman el Ms. XII. Esta música está editada en dos volúmenes por la Fundación Calouste Gulbenkian en su serie Portugaliae Musica, en los que Querol Gavaldá analiza y transcribe las obras.

Este musicólogo, citando las investigaciones que sobre la autoría de los manuscritos hizo el Padre Llordén (1960, pp. 179193; 1964, p. 90), corrobora que los manuscritos II, IV, VII, VIII y IX fueron escritos por el calígrafo coral Pedro Marañón hacia 1631 y que los números X y XII fueron copiados por Tomás José García Esquivel en 1777 y 1769, conteniendo la música de Brito.

Como hemos comentado anteriormente, que la música del maestro luso se conserve en buen estado no es una casualidad, sino que debe al gran interés que el músico tenía por ello y que demostró en una carta autógrafa de 1629. En dicha carta contenida actualmente en el Legajo 556, $n^{\circ} 1$ del archivo de la catedral de Málaga, el músico pide expresamente al Cabildo que se trasladen a pergamino las obras que tiene compuestas preocupado porque su música pudiera perderse. Un hecho que no era muy habitual y que nos demuestra su deseo:

El Racionero Estevan de Brito, maestro de capilla de esta santa iglesia de Málaga, digo que yo tengo, hechas y compuestas muchas cossas de música como son, Missas, Magnificas, Psalmos, Hymnos, y otras cosas que faltan, y son muy necesarias para el servicio de la dicha iglesia, las cuales por andar en papeles sueltos se pierden cada día.

A vuestra merced suplica mande se punten en pergamino, de el punto y letra que fuere más a propósito, para que assi duren, y el servicio del choro, no padezca, por falta de las dichas obras. El maestro Estevan de Brito (firmado) ${ }^{76}$.

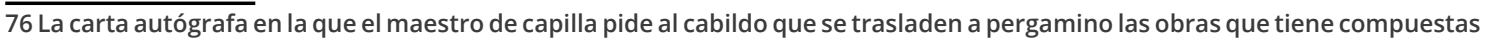
la hemos localizado en E-MA, leg. 556, nº 1. 
De Badajoz a Málaga: Trayectoria del Portugués Estêvão de Brito como Maestro de Capilla Héctor Archilla Segade

La respuesta que acepta la petición aparece escrita posteriormente en los siguientes términos:

Nos el Doctor Don Diego de Trejo arcediano y canónigo en la santa iglesia de Málaga gobernador de la dicha ciudad y su obispado por el llustrísimo y Reverendísimo Señor Cardenal de Trejo obispo de Málaga y presidente de Castilla, encargamos a Pedro Marañón escriptor de libros vecino de la ciudad, que escriba en pergamino lo contenido en la petición supraescripta, y hecho acuda a nos para que lo hagamos corregir, ver y tasar A doce de noviembre de mil seiscientos veintinueve años El Doctor Trejo (firmado).

Quedaría ahora la labor de ahondar en futuras investigaciones para comprobar si todas las obras contenidas en estos manuscritos son realmente del músico portugués o si alguna de ellas pudiera ser de otros compositores tal y como sugiere Ress, y por otra parte, animamos a la revisión de otras fuentes primarias como protocolos notariales que aporten nuevas informaciones acerca del músico.

\section{Conclusiones}

La búsqueda de documentación que aporte nuevos datos a una investigación será útil siempre que complete, corrija o ayude a reinterpretar lo expuesto con anterioridad. Esta ha sido la intención al elaborar este artículo con el que hemos tratado de completar espacios que estaban por llenar, mediante el vaciado de nuevas actas capitulares y otros documentos aún sin tener en cuenta, además de revisar y corregir documentación ya encontrada con objeto de reconstruir los hechos históricos de la forma más rigurosa posible.

Gracias a este proceso hemos podido explicar aspectos relativos a la marcha del músico portugués Estêvão de Brito y su 
De Badajoz a Málaga: Trayectoria del Portugués Estêvão de Brito como Maestro de Capilla Héctor Archilla Segade

relación con el Cabildo pacense que no estaban del todo claros en investigaciones anteriores. De esta manera, se detalla la marcha del músico de Badajoz, el proceso de oposición en la catedral de Málaga, las relaciones tensas con el deán de la catedral de origen y los posteriores contactos de dicha catedral con el músico que pasaron a ser cordiales.

Otro tema que estaba por aclarar y detallar era el proceso de nombramiento del nuevo maestro de capilla en la catedral de Badajoz después de la marcha de Brito. Una cuestión que había sido presentada de manera inexacta, debido al desconocimiento de bastantes noticias que, aunque contenidas en las actas de cabildo, no habían sido expuestas hasta el momento. Después del vaciado completo de estos libros de actas, podemos aportar esta información para presentar tanto a los protagonistas que participaron en el proceso de sustituir al maestro portugués como para exponer la medida en que lo hizo cada uno de ellos.

Un dato relevante ligado con esa relación del músico luso con el Cabildo pacense, que muestra la gran influencia que ejerció después de marcharse a Málaga y hasta su muerte, se pone de manifiesto a través del nombramiento sucesivo a propuesta de Brito de los cuatro únicos maestros de capilla portugueses que estuvieron al frente de la capilla musical de Badajoz. Estos fueron Manuel Rodríguez Galván, Juan Díaz, Francisco Pinto Piñero y Alonso Vaz de Acosta.

El proceso de oposición de la plaza de maestro de capilla, que finalmente ocuparía Brito en Málaga, a pesar de haberla tratado anteriormente, ha sido otro de los objetivos que nos planteamos para presentar así transcripción de aquellos asientos de las actas de cabildo que hablan sobre ello, además de identificar las fuentes primarias en las que se encuentran para facilitar la consulta de cualquier interesado por este tema.

Asimismo, se presentan aquellas noticias relacionadas con el período de 1613 a 1641 en el que el maestro luso se encargó de la dirección de la capilla musical de la catedral Málaga. Aunque no 
De Badajoz a Málaga: Trayectoria del Portugués Estêvão de Brito como Maestro de Capilla Héctor Archilla Segade

son muchas, la mayoría de ellas inéditas nos dan buena cuenta de las labores compositivas, interpretativas y didácticas que el músico desarrolló en esta ciudad además de ponerlas en valor.

La colección de música que de Brito afortunadamente se conserva en buen estado dentro del archivo de Málaga no es fruto de la casualidad. Presentamos el documento que muestra la petición explicita del citado compositor para que su música fuera conservada y no se perdiera, solicitando expresamente que se hiciera copia de sus composiciones en pergamino; un hecho poco común que muestra a un compositor preocupado por su trabajo.

\section{Referencias}

ALEGRÍA, José Augusto. Brito, Estêvão de. In: CASARES RODICIO, Emilio (Ed.). Diccionario de la Música Española e Hispanoamericana, vol. 2. Madrid: SGAE, 1999-2003, p. 704-706.

ARCHILLA, Héctor. Estêvão de Brito un maestro de capilla portugués en las catedrales de Badajoz y Málaga. In: MARÍN LÓPEZ, Javier (Coord.). Musicología global, musicología local. Madrid: Sociedad Española de Musicología, 2013, p. 1932-1936.

ARCHILLA, Héctor. Estilo y técnica del maestro Estêvão de Brito en su Motectorum liber primum de la catedral de Málaga. In: LOLO, Begoña (Coord.). Musicología en el siglo XXI: Nuevos retos, nuevos enfoques. Madrid: Sociedad Española de Musicología, 2018, p. 105-124.

ARCHILLA, Héctor. Músicos portugueses en España durante el reinado de Felipe III|: El maestro Estêvâo de Brito. 2016. Tesis Doctoral Universidad de Extremadura.

ARCHIVO CATEDRAL DE BADAJOZ. Libro de Actas Capitulares. Cabildo Pleno. Desde 4 de marzo de 1610 hasta 24 de marzo de 1616.

ARCHIVO CATEDRAL DE BADAJOZ. Libro de Actas Capitulares. Cabildo Pleno. Desde 5 de febrero de 1621 hasta 20 de agosto de 1627. 
De Badajoz a Málaga: Trayectoria del Portugués Estêvão de Brito como Maestro de Capilla Héctor Archilla Segade

ARCHIVO CATEDRAL DE MÁLAGA. Libro de Actas Capitulares. Desde 15 de abril de 1615 hasta 19 de mayo de 1620.

ARCHIVO CATEDRAL DE MÁLAGA. Libro de Actas Capitulares. Desde 16 de marzo de 1633 hasta diciembre de 1639.

ARCHIVO CATEDRAL DE MÁLAGA. Libro de Actas Capitulares. Desde 3 de enero de 1609 hasta 3 de abril de 1615.

ARCHIVO CATEDRAL DE MÁLAGA. Libro de Actas Capitulares. Desde 6 de febrero de 1640 hasta 21 de febrero de 1648.

BARRIOS, Pilar. La música en la catedral de Coria (Cáceres) (1590-1755). Cáceres: Servicio de publicaciones Universidad de Extremadura, 1999. 792p.

KASTNER, Macario S. La música en la Catedral de Badajoz (años 1601 1700). Anuario Musical, Barcelona, n. 15, p. 63-83.

LLORDÉN, Andrés. Notas históricas de los escritores de libros corales de Málaga. Anuario Musical, Barcelona, n. 15, p. 179-193, 1960.

LLORDÉN, Andrés. Notas históricas de los maestros de capilla en la catedral de Málaga (de 1583 a 1641). Anuario Musical, Barcelona, n. 19, p. 71-93, 1964.

MARTín, Antonio. Catálogo del archivo de música de la Catedral de Málaga. Granada: Consejería de Cultura Junta de Andalucía, 2003. 1136p.

QUEROL, Miguel. Portugaliae Musica. Série A. Estêvão de Brito. Vol. 1. Motectorum Liber Primus Officium defunctorum Psalmi Hymnique per Annum. Fundação Calouste Gulbenkian: Lisboa, 1972.

QUEROL, Miguel. Portugaliae Musica. Série A. Estêvão de Brito. Vol. 2. Obras diversas. Fundação Calouste Gulbenkian: Lisboa, 1976.

RESS, Owen. The music of Estêvão de Brito in context. In: MÃO DE FERRO, Fernando (Ed.). Escola de música da Sé de Évora: Conferencias. Lisboa: Colibri, 2019. p. 50-54.

SOLíS, Carmelo. El archivo musical de la Catedral de Badajoz. Una aportación documental. In DE PERSIA, Jorge (Ed.). El Patrimonio musical de Extremadura: Cuaderno de trabajo $n^{\circ} 1$. Trujillo: Ediciones de la Coria, Fundación Xavier de Salas, 1993. p. 15-38. 
De Badajoz a Málaga: Trayectoria del Portugués Estêvão de Brito como Maestro de Capilla Héctor Archilla Segade

SOLís, Carmelo. Maestros de capilla, organistas y organeros portugueses en la Baja Extremadura (siglos XVI-XVIII). Revista Portuguesa de Musicología, Lisboa, n. 1, p. 87-96, 1991.

TORRENTE, Álvaro (Ed.). Historia de la música en España e

Hispanoamérica, vol 3. La música en el siglo XVII. Madrid: Fondo de Cultura Económica de España, 2016. 787p.

\section{Publisher}

Universidade Federal de Goiás. Escola de Música e Artes Cênicas. Programa de Pós-graduação em Música. Publicação no Portal de Periódicos UFG.

As ideias expressadas neste artigo são de responsabilidade de seus autores, não representando, necessariamente, a opinião dos editores ou da universidade. 